\title{
Recognizing Resilience: Exploring the Impacts of COVID-19 on Survivors of Intimate Partner Violence
}

\section{Dessie Clark ${ }^{1}\left(\mathbb{D} \cdot\right.$ Rebecca Jordan $^{2}$}

Accepted: 4 November 2021 / Published online: 20 November 2021

(c) The Author(s), under exclusive licence to Springer Science+Business Media, LLC, part of Springer Nature 2021

\begin{abstract}
This study explores self-reported impacts of the COVID-19 pandemic on several facets of IPV survivor well-being, such as mental health, economic stability, food security, and resilience. Semi-structured interviews were conducted with survivors of IPV. Qualitative data were collected on variables related to mental health, economic stability, food security, and resilience. The findings of this study suggest that while survivors of intimate partner violence (IPV) face a variety of challenges posed by COVID-19 (e.g., employment, income, etc.), they identify themselves as resilient. Our findings also show that while survivors of have faced setbacks due to COVID-19, variables such as mental health and well-being have improved. Our findings suggest that while the pandemic has certainly impacted survivors, and included setbacks or delays, survivors have seen improvements in several areas. Our data suggest that these improvements, in the face of difficulties, is because of the overwhelming resilience of survivors.
\end{abstract}

Keywords COVID-19 - Intimate partner violence $\cdot$ Resilience $\cdot$ Mental health . Qualitative

\section{Introduction}

In 2020, an unprecedented pandemic, COVID-19, produced devastating impacts on a global scale. The pandemic has caused disruption to daily life including changes in work, school, and childcare. In order to slow the spread, "Safer at Home", both a rallying cry and campaign, has become a way to encourage people to self-isolate.

Dessie Clark

dessieclark@umass.edu

Rebecca Jordan

jordanre@msu.edu

1 University of Massachusetts, Amherst, MA, USA

2 Michigan State University, East Lansing, MI, USA 
City and state-wide stay-at-home orders stated that individuals were expected to stay indoors except for essential activities or work for essential businesses [5]. However, for survivors of intimate partner violence (IPV), home may not be the safest place, particularly if these survivors are living with an abusive partner [6, 13, 27]. IPV is defined as physical or sexual violence, stalking, psychological aggression, or coercion by a past or current intimate partner.

Early research suggests that many of the strategies public health officials have enacted to help mitigate the spread of COVID-19 have resulted in greater risk for adverse mental health and physical violence, particularly those facing IPV [5, 6, 18, 19]. Additionally, these COVID-19 protocols, such as stay-at-home orders, may give abusive partners more freedom to perpetrate abuse without consequence [6]. In this paper, we seek further evidence to determine COVID-19 impacts on IPV survivors. In particular, we focus on self-reported impacts of the COVID-19 pandemic on several facets of IPV survivor well-being, such as mental health, economic stability, food security, and resilience.

As a pandemic on this scale has not happened in recent history, work has drawn on natural disaster literature to assess the impacts that COVID-19 may have on IPV survivors, which suggests that natural disasters tend to increase the frequency and severity of IPV [8, 12, 28]. COVID-19 has brought societal disruption, lack of access to, and loss of support services that one can expect in a natural disaster. These conditions may also contribute to intensified and lengthy loneliness that a pandemic can bring [15].

Further, by virtue of being an IPV survivor, these individuals may be more reluctant than the general population to seek aid from services. Kaukinen [25] notes that in general, survivors may be unable or unwilling to access necessary services such as healthcare, mental healthcare, and other victim services such as housing or advocacy services. Additionally, the modes by which services such as healthcare, housing support, and even legal services (e.g., court proceedings, advocates, etc.) are offered have also changed because of COVID-19. One obvious area of concern is that while many services, such as mental healthcare, have changed to believed-tobe-safer virtual access (e.g., Wi-Fi and phone), survivors might experience increased safety risks given that the abuser may be present in the home [25, 44].

Individual, community, and societal risk factors for IPV have likely been exacerbated by COVID-19 [37]. COVID-19 has taken a disproportionate health and financial tolls on racial minorities and immigrant communities. These communitieis are more likely to face family illness, unemployment, or loss of a loved one $[10,16]$. Individual factors, such as mental health issues, may be both a result of and risk factor for IPV [17, 26]. This is further cause for concern as an increase in mental health issues has been noted during COVID-19 [7, 18, 19]. This is particular cause for concern for African American and Hispanic women who are more likely to experience exacerbated mental health consequences related to IPV [29, 41, 49]. COVID19 may impose further problems because survivors must stay away from people in their social network who can provide support and validate their experiences [35].

Given its ongoing nature, data that capture the impact of the pandemic on IPV survivors are limited. Initial survey data, however, paint a complex picture (see Table 1). Clearly more investigation providing clarity around COVID-19's impact 
Table 1 Relevant literature

Reports suggest that the pandemic greatly increased the severity of IPV as evidenced by increased calls into police and other emergency services worldwide as reported by NYTimes (reporter [50])

IPV related reporting/request for help calls USA

increased with 9/20 major US metropolitan areas reporting an increase of $20 \%$ or greater; [22]

increased in 14 US cities; [30]

increased (18\%) in San Antonio; Texas Management [33]

increased (27\%) in Jefferson County, Alabama; [36]

increased (10\%) in New York City, New York; [39]

$I P V$ related arrests in the USA

increased (22\%) in Portland, Oregon; Portland Police Bureau, [43]

$I P V$ related reporting/request for help calls International to USA

tripled in China's Hubei province; Fraser, 2020

increased in Argentina by 25\%; [53]

increased in Cyprus by 30\%; [54]

increased in Singapore by 33\%p [54]

Not all studies found the same rate of increase, with some finding higher rates initially and then decreasing or simply decreased (e.g., [2, 24, 42]

Certainly, the type of emergency call matters (Rose et al., 2020); see descriptions below

A survey with a sample recruited in the US through social media [23] found of the 2441 respondents surveyed in the study, $18 \%$ of the respondents indicated IPV currently

Some researchers have found that hotline traffic is down (Fielding, 2020). As a caveat, these authors highlight that this could be because survivors are home with their abusers and unable to use call services

In February 2020, 40\% of calls to hotlines were survivors experiencing a crisis point (Fromison et al., 2020). Crisis point is defined as survivors being in distress, imminent danger, and an urgent need to leave the home immediately. However, in March 2020, following stay-at-home orders, $60 \%$ of hotline calls consisted of survivors at crisis point (Fromison et al., 2020). This suggests while hotline traffic may be down, there is a notable uptick in the severity of calls

in Mexico City found a decrease in calls to a local hotline during the stay-at-home period [48], there is evidence that an increase in psychological (versus physical) violence may be occurring, which was corroborated with evidence from other prominent international cities [3] in Spain; Perez-Vincent \& Carreras (2020) in Brazil; (ref. in [48])

In Italy, researchers found a decrease of survivors accessing services during the stay-at-home orders [4]. These authors, again, caution that this finding is not due to a decrease in violence, but rather a decrease in help-seeking and resource provision [4]

on survivor well-being is warranted. One particular measure of well-being is resilience. Individual resilience has been defined in many ways in the last $50+$ years. In one sense, individual resilience can be considered a suite of traits or characteristics. These include but are not limited to optimism, adaptability, faith in positive outcome, self-efficacy, tolerance of negative emotions, control realism, action/goal orientation, and engaging support structures (reviewed in [9]). In another sense, resilience can be seen as a process whereby one engages in positive change in the face of adversity (e.g., [32]). The latter requires one to engage in adverse events and reflect on the recovery process as opposed to a selection of measured traits. 
Certainly resilience has been discussed in the context of IPV survivors both in terms of a process in which individuals can engage to overcome threat (e.g. [40],) and as a characteristic important in facing ongoing stress or disaster (e.g., [21]). In fact, some work suggests that resilience is higher in women who have experienced IPV and used shelter programs [20] and that this resilience may be a protective factor [14]. In particular, self-efficacy, hope, and coping skills have been identified as critical to resilience [14]. Resilience correlates with less mood disturbance in individuals who have experienced IPV [46]. Additionally, individuals experiencing continual stress and IPV report lower moods and less resilience [52]. Relative to the pandemic, mental health, and mood status can also greatly impact resilience (e.g., [47]). Though resilience is associated with personal traits, which may have taken a long time to develop [45]. it has been suggested that resilience can be fostered by other relational contexts such as families and communities and that resilience can be developed (e.g., [34]).

This notion of community resilience or sometimes called community disaster resilience, is characterized by (a) The ability of a complex human social system to retain or regain function in the the face of a disturbance or disaster (e.g., Covid19) (b) Includes interconnected systems including individuals and the groupings/institutions of which individuals comprise and (c) Is characterized by the capacity in which important systems are affected, changed, and ultimately recovered from the disturbance (much like individual resilience; e.g., [38]. In this work, we focus on resilience because the COVID-19 pandemic represents a novel threat in the face of ongoing stress known to impact survivor communities. In addition, COVID-19 has been suggested to intersect with mental and physical health, individual resilience, the economy, the food system; all of which greatly impact community resilience [44]. Given the ways in which these issues may interact and worsen outcomes for IPV survivors this paper explores experiences of IPV survivors on community resilience elements during the COVID-19 pandemic.

\section{Methods}

As a component of a larger mixed-methods study examining a clinical intervention, participants were invited via flyer at a domestic violence agency in the southern United States. This agency is the only IPV agency in the county and serves approximately 1,500 women, children, and men annually. This agency offers a 24-h crisis hotline, emergency shelter, housing programs, and a variety of ancillary services (e.g., counseling, legal, career development, etc.).

\section{Sample}

Our sample consisted of participants who were using services at a domestic violence agency in Texas at the time of their initial interview. This sample $(\mathrm{N}=12)$ consisted of all women participants ranging in age from 25 to 65 . Regarding race/ethnicity, our sample was diverse with 33\% White, 25\% Hispanic, 25\% Black, $8 \%$ Vietnamese, 
and $8 \%$ Indian. Our sample was also highly educated with all participants attending some form of post-secondary training (33\% Some College, 25\% Associate's Degree, 17\% Bachelor's Degree, 17\% Vocational Training, 8\% Advanced Degree). None of the survivors indicated being in crisis, living with an abusive partner, or experiencing any abuse in the 3 months prior to the interview. As such, our results should not be extrapolated to survivors who may currently be receiving more intensive services or are facing current or ongoing abuse. Our sample represents survivors who have previously used intensive services (e.g., shelter), but have since moved on to using ancillary services such as services for mental or physical health.

\section{Procedure}

COVID-19 reached the United States in March 2020 and has significant impacts on the lives of all Americans. As such, COVID-19 was a large topic of conversation in these interviews and this unanticipated data became the source for this emergent paper. For this paper, we focus only on aspects of these conversations in relation to COVID-19. This work was reviewed and approved by the University's Institutional Review Board.

Participants self-nominated and were eligible if they were over 18 and currently receiving services from the agency. The focus of this paper is on the qualitative semi-structured interview data. Questions included open-ended responses related to mental health, finanical hardship, food security, health care, and psychological resilience. We focused our interview on these five elements of resilience because we were interested in community resilience as described above. Participants were interviewed in July and August 2020, with interviews taking roughly one hour. All interviews took place by phone and were audio recorded. All data were stored on secure servers at a large midwestern university. Identifiable information was removed from transcripts and stored separately. A licensed counselor was available for survivors to be referred to should they become distressed during the interview.

\section{Analysis}

A total of 12 people were interviewed. All audio recordings were sent to an external transcription agency approved for this type of research. The transcripts were analyzed using a Inductive Content Analysis (ICA), which involves collaborative reading of transcripts to examine the details of the semi-structured interview [51]. The goal of ICA methodology is to unobtrusively inspect the responses to questions about the state of the major categories of resilience as defined above. In particular, we wanted to simply organize information provided in the interview to understand the impact of the COVID-19 pandemic on survivor health, well-being, food security and financial status. We felt that ICA would allow us to inductively identify issues for future analysis $[11,55]$. We extracted the concepts after our initial review (Table 2). After a discussion, we retained all concepts and undertook another review of the transcripts. During this review, we sought to capture which survivors 


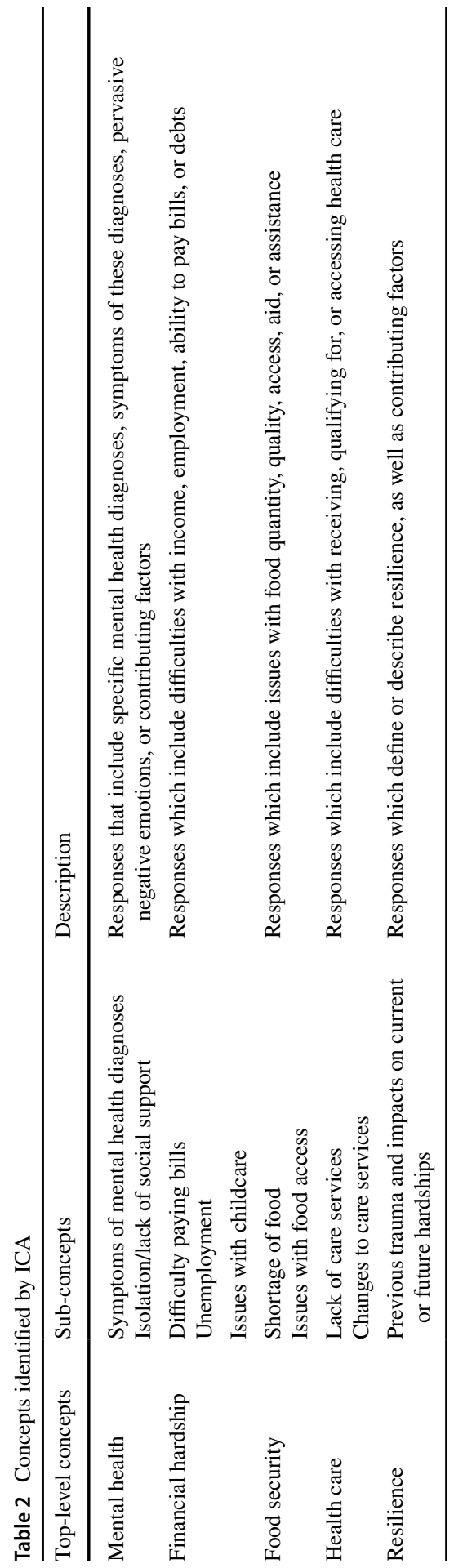


experienced which aspect of hardship with respect to health, well-being, and financial status. Following the second round of coding, a coding consistency check was completed by an independent coder. The coder was provided with the research objectives, categories, and descriptions of each category. The coder then was asked to code previously coded text into existing categories. The independent coder was in agreement and the findings were compiled. The results below follow a suggested ICA template for reporting findings including a brief description of each concept (Table 2), headings which demonstrate top-level concepts, and key quotes [51].

\section{Results}

In summary, our data suggest that COVID-19 has impacted a variety of key variables for survivors including mental health, financial hardship, food security, health care, and resilience.

\section{Mental Health}

Overall, most survivors reported that their mental health improved. One survivor described the improvement saying, "I don't have that feeling that I used to have anymore that used to make me feel like very, very low." (Black, 33) However, our results suggest that while there have been improvements, the majority of survivors still reported issues with mental health that impact daily life. In some cases, that was related to COVID-19, "Um, I would just say it's the-it is the psychological scare, as well as the, you know, um, the effect of, um, you know, health wise, like you have a low immune system." (Latina, 36) In other cases, that was due to events that happened prior to the pandemic.

The only thing they said was um, that I had got the - I've been uh - I haven't been able to sleep because I would be like re-seeing the whole um, traumatic event that I had experienced with my ex. Um, but they were saying I had like a little bit of PTSD going on. (Black, 33)

With regard to coping behavior, however, only one individual reported an increase in alcohol consumption and made clear that this was very limited because of children in the home. Others reported less consumption as related to financial and social constraints. Other behavior in regards to aclohol or drug use was not discussed among any of the survivors. For many, loss of social support and interaction had negative effects on well-being. One participant described the toll that COVID19 took on an already limited social circle, "Um, not - I'm not - I don't really - I don't have any friends. Um, I only have a few family members that can help me, you know, maybe get together or something, but with this COVID-19, it's been very difficult to." (Latina, 47) Other participants echoed this noting the inability to go to church, celebrate positive life events, or be with trusted family or friends was difficult. However, some participants did note alternative ways to interact, such as celebrating birthday parties virtually through Zoom. 


\section{Financial Hardship}

Many survivors reported increased financial hardship during the pandemic. This was made more difficult because of fears around lack of supply, which caused some to stock up on food and household necessities versus paying certain bills. The majority of participants reported unemployment. Of those who were able to retain employment during this time, most experienced reduced hours. In some cases, work contributed to mental health concerns.

I was still working and um, one thing that did bother me was that everyone else went home to work from remote because of their positions, but they left me to stay there and I had to go there every day. That kinda bothered me mentally a little bit. (Black, 33)

Minor, but necessary bills, like internet for school-aged children were still taxing for some participants. "Um, we got reduced, uh, for like Internet. That's about it, like the internet, Wi-Fi. Um, yeah, the \$10 a month. So, it's, um-I say that's my son's though...But yeah, it's very difficult to pay \$10, but yeah." (Latina, 36) Some participants noted the lack of financial flexibility during this time and the impact it had on their overall financial situation.

And, you know, out of concern, like when I contacted the landlord to ask them like, if they would, you know, require us to continue paying because there were rumors, I guess, in the news saying that, you know, landlords wouldn't be able to evict. But, you know, my landlord was like, "No, you know, we're still requiring people to pay rent." So, you know, it's just, it's like, you know, all these, uh, - I feel like it's really inconsiderate. (Indian, 26)

Stress related to loss of childcare and working from home or reduction of working hours were noted. In some cases, participants noted the combination of working with a loss of childcare.

Well, my son - I have a little boy so I live here by myself but I don't really get a break. Cuz um, like when I go to work on my lunchbreak I used to get a hour, but since COVID is messing up the daycare hours I only get a 30-minute lunch so really by me going down the street grabbing something, that's all the free time I ever have. (Black, 33)

Many also indicated ongoing financial issues and that though the pandemic made things worse, it exacerbated existing financial problems rather than posing new ones. Many reported not having a budget for entertainment, but it was not clear if this budget existed before the rise of COVID-19. For some, choosing to pay home entertainment bills (e.g., streaming services) was even more critical during the pandemic because of a need to entertain children in the home while working. A number of survivors relied on state and federal aid, and those individuals reported that this aid stayed constant during the pandemic. 


\section{Health Care}

Less widespread in those interviewed were issues around health care. Only a few referenced total lack of healthcare, with some saying they still retained access to healthcare but the access had changed. The type of care impacted was described was non-emergency, ongoing treatment around pain (e.g., injections, marijuana, etc.). For example, one participant noted the lack of access to healthcare.

Yeah. It's impacted it a lot because there's doctors that I can't get in to see because of COVID and there's not like pain management doctors that I need to see that I can't see because they're not taking new patients because of COVID. (White, 32)

This lack of non-essential care caused many to seek less effective alternative treatments such as CBD.

\section{Food Security}

Half the sample reported having low or very low levels of food security-noting issues with changes in food and food scarcity. While many reported a change in food because of supply chain limitations, some have reported a reduction. One participant described issues with food shortage,

Yeah. Um, like I said when everything first went crazy like getting meat in the store was impossible. Like there was no chicken. There was no beef. There was just nothing. There wasn't even pork on the shelves. Like I mean like it was crazy. Luncheon meat was almost nonexistent. (White, 32)

Some of the issues with food access are related to financial strain, while others are related to difficulty getting to the necessary stores. This difficulty was driven in part by transportation issues, store closures, or individuals being immunocompromised.

Um, well, sometimes I try to go early in the morning when they have the um - the fair or compromised systems that can go in the store, but sometimes it's hard for me early in the morning so I've been trying to go on Fridays early in the morning before I go to work or as soon as I get off from work at noon.

(Black, 33)

This has caused some to change locations where people shopped and in some cases to locations that had less variety or less healthy options (e.g., dollar stores, convenience stores, etc.). Participants also noted the ways in which children made it more difficult to shop for and provision food. "I made sure my son ate. I was the one that [didn't]...If I would eat-You know, me eating, I would eat smaller portions. And the spoils is what I eat, you know." (Latina, 36) In addition, some described needing to buy food in different quantities, which resulted in more or uneven spending. 


\section{Resilience}

Despite the myriad concerns, all survivors rated themselves as being psychologically resilient. The most common theme in defining their resilience was the fact that they had faced challenges and continued to persevere. One participant said, "As Rocky says, it's not about how hard you hit, it's about how hard you get hit and keep moving-move forward." Survivors also referenced that the ability to keep moving forward is difficult. (White, 46).

Because I feel like every time, I have a setback, I still get back up and I still continue on. I don't let it keep me down. Even though it's extremely hard, uh, I see myself as someone who is strong just because I don't - like I said, I don't let myself just stay down. I continue. I move on. (Latina, 45)

Most survivors noted that they had been through hard times in their lives, but that they had overcome these struggles. One participant commented on the severity of these challenges, "I've fallen many times. I should be dead. It's just-I keep coming back." (Black, 54).

\section{Discussion}

Aligned with the noted difficulties with mental health in the general population because of COVID-19, our participants reported symptoms of mental health that interfere with their daily life. However, most survivors did note that while these difficulties existed, mental health symptoms had generally improved. As noted in the introduction, virtual mental health services might not be adequate for survivors. The literature suggests this could be related to issues of access (e.g., lack of phone or wifi) or issues of safety (e.g., abusive partner in the home). Our sample all participated in interviews by phone which lasted approximately an hour and none reported living with an abusive partner. This suggests the participants in our sample may be able to safely access virtual services which could in turn bolster their mental health. This lack of access is particurlarly troubling for people of color who may already be experiencing disproportionate issues with access to healthcare due to COVID-19 [10, 16]. One important consideration is that the survivors in this sample all identified as post-crisis point, not co-habitating with an abusive partner, and are actively gaining or have gained services. In that way, these individuals may be experiencing better mental health outcomes than survivors who are in crisis or do not have access to services.

While COVID-19 has had implications for social connectivity, in our results, social support among participants was fairly mixed. As suggested in the literature, participants found themselves struggling to connect with others because of limitations by COVID-19. However, other participants noted new ways to engage such as connecting virtually to have Zoom birthday parties. Our findings do 
suggest that while social support was negatively impacted for some, participants self-reported improvements in mental health.

With regard to employment, adequacy of financial support, and economic hardship, our results are as expected. As the literature suggests, COVID-19 did result in increased financial stressors related to employment status and bill payment. While COVID-19 has broadly impacted personal finances, it has been particularly taxing on people of color which make up the majority of our sample $[10,16]$. There was evidence that survivors in this study experienced reduced access to food because of supply chain interruptions driven by the pandemic, financial hardship, and difficulties in securing high quality food. Participants described looking to non-traditional food sources such as Dollar Tree which anecdotally have a more limited range of food choices, with most of those options being processed rather than nutrient dense foods.

In our case, the key finding from our results was that of individual resilience. Despite the various hardships that survivors have faced, and are continuing to face, all of our participants described themselves as resilient. While many around the world are experiencing inadequate income, lack of access to resources, and isolation for the first time in the face of the COVID-19 pandemic, there is ample research to support that these are issues survivors often grapple with prior to the pandemic [1]. As such, these issues are not entirely foreign to survivors and many may be familiar with navigating the systems through which these issues are mitigated (e.g., unemployment, food stamps, etc.). While survivors identified social support as being limited, most survivors are not strangers to isolation which, again, has been well-documented in the literature [1]. Another key aspect of resiliency is a tolerance for negative emotions [21]. For survivors, these negative emotions may have been present before COVID-19, particularly when the survivors were in the crisis which led them to seek services, and therefore could seem more tolerable. Many of these specific hardships, therefore, overlap experiences as a survivor and the pandemic.

Our study is not the first to suggest resilience is higher in women who have experienced IPV (e.g., [20].). Most studies of these women were conducted directly following the crisis period ([47]; and similar to the individuals in our study) and some researchers have discussed resilience as a protective factor in line with social support and other personal strengths [14]. Our findings are in line with previous work that suggests resilience correlates with less mood disturbance in individuals who have experienced IPV [46]. While the pandemic has impacted mental health and mood status in the general population, our findings suggest that survivors have reported improved mental health and increased resilience. Research suggests that individual resilience is associated with personal traits, but that it can also be fostered [45]. In this case, resilience which may have developed as a result of navigating IPV, may help survivors navigate future times of crises or hardship, including a global pandemic.

Further it is possible that psychological resilience will not only help survivors with navigation in times of crisis but in tandem with other elements of pscyhological health, may also result in economic improvement. In this way, individual resilience, and mental health may be linked to other aspects of community resilience. For example, Luthans et al. [31] review their concept of psychological capital or 
psycap. Such capital is comprised of an individual's efficacy, optimism, persistance, and resiliency. As summarized above, these personal factors are highly interrelated to the concept of resiliency and are able to be cultivated [34]. Over the course of a year, Luthans et al. [31] have calcuated the impact of psycap not only on mental health but also on one's strategies around employment and financial decisionmaking. These authors have found that a simple intervention in improving psycap resulted in a $200 \%$ increase on this hypothetical financial return. Such returns can then be related to subsequent financial and physical health. It would seem then that interventions focused on community and psychological esiliency such as psycap can have wide reaching implications for survivor wellbeing and other members of their community.

\section{Conclusion}

Our results leave us with several questions, could the experiences with IPV and engaging agency services, including psychological support, have resulted in increased resilience relative to the general population? In addition, given that resilience can be recharged by social support (e.g., [56]) what are the implications for this group of survivors who are seeing mixed levels of this support? These questions, in addition to those focused on resilience below, form the basis of future research.

Additionally, our findings suggest several key takeaways. First, the survivors in this study are currently facing concerns with finances, employment, mental health, social support, and well-being; all of which affect the capacity of a community to adapt and recover (e.g., [38]). While these concerns are grave, and certainly should not be taking lightly, survivors do note some improvements. The participants in this study are all post-crisis and these findings are what one would expect and hope for had the pandemic not occurred. However, these findings are promising in light of the pandemic. Our findings suggest that while the pandemic has certainly impacted these variables, and included setbacks or delays, survivors define themselves as resilient. While times are certainly hard, and the outlook has been grim, survivors seem poised to face these setbacks head on. In applying a community resilience scheme, we suggest further study into both preparation for and response to disaster faced by vulnerable communities like the IPV survivors in this study (e.g., [57]). Identification of vulnerabilities should not only include all aspects of health and well-being as is often considered but also should include all aspects of survivor livlihood such as finances, food, transportation, and social networks. Identifying the latter is essential for all communities who have the potential to be affected and we argue that connecting these communities in an effort to consolidate strengths will result in redundancy in system function which is critical in the face of system disturbance. Doing so will require a broader approach to how vulnerable communities are supported through disasters.

Acknowledgements We would like to thank the survivors who gave their time to share their experiences with us for this study. We would also like to thank all who have reviewed and provided feedback on this work. 


\section{Declarations}

Conflict of interest The authors declared that there is no conflict of interest.

Ethical approval This study received ethical approval through an Institutional Review Board.

Informed consent All participants completed an informed consent procedure.

\section{References}

1. Arroyo, K., Lundahl, B., Butters, R., Vanderloo, M., \& Wood, D. S. (2017). Short-term interventions for survivors of intimate partner violence: A systematic review and meta-analysis. Trauma, Violence, \& Abuse., 18(2), 155-171.

2. Ashby, M. (2020). Changes in police calls for service during the early months of the 2020 coronavirus pandemic.

3. Arenas-Arroyo, E., Fernández-Kranz, D., \& Nollenberger, N. (2020). Can’t Leave You Now! Intimate Partner Violence under Forced Coexistence and Economic Uncertainty.

4. Barbara, G., Facchin, F., Micci, L., Rendiniello, M., Giulini, P., Cattaneo, C., \& Kustermann, A. (2020). Covid-19, lockdown, and intimate partner violence: Some data from an italian service and suggestions for future approaches. Journal of Women's Health, 29(10), 1239-1242. https://doi.org/ 10.1089/jwh.2020.8590

5. Boserup, B., McKenney, M., \& Elkbuli, A. (2020). Alarming trends in US domestic violence during the COVID-19 pandemic. American Journal of Emergency Medicine, 91(20), 3-5. https://doi.org/ 10.1016/j.ajem.2020.04.077

6. Bradbury-Jones, C., \& Isham, L. (2020). The pandemic paradox: The consequences of COVID-19 on domestic violence. Journal of Clinical Nursing, 29(13-14), 2047-2049. https://doi.org/10.1111/ jocn. 15296

7. Buttell, F., \& Ferreira, R. J. (2020). The hidden disaster of COVID-19: Intimate partner violence. Psychological Trauma: Theory, Research, Practice, and Policy, 12, 2017-2018. https://doi.org/10. $1037 /$ tra0000646

8. Buttell, F. P., \& Carney, M. M. (2009). Examining the impact of hurricane katrina on police responses to domestic violence. Traumatology, 15(2), 6-9. https://doi.org/10.1177/1534765609 334822

9. Connor, K. M., \& Davidson, J. R. (2003). Development of a new resilience scale: The ConnorDavidson resilience scale (CD-RISC). Depression and Anxiety, 18(2), 76-82.

10. Eligon, J., Burch, A., Searcey, D., \& Oppel Jr, R. (2020). Black Americans face alarming rates of coronavirus infection in some states. New York Times, April 7.

11. Elo, S., \& Kyngäs, H. (2008). The qualitative content analysis process. Journal of Advanced Nursing, 62(1), 107-115.

12. Ferreira, R. J., Cannon, C., \& Buttell, F. (2020). COVID-19: Immediate predictors of individual resilience. Sustainability, 12(16), 6495.

13. Froimson, J. R., Bryan, D. S., Bryan, A. F., \& Zakrison, T. L. (2020). COVID-19, Home Confinement, and the Fallacy of "Safest at Home." American Journal of Public Health, 110(7), 960-961. https://doi.org/10.2105/ajph.2020.305725

14. Gillespie, B., Chaboyer, W., \& Wallis, M. (2007). Development of a theoretically derived model of resilience through concept analysis. Contemporary Nurse: AJournal for the Australian Nursing Profession, 25(1-2), 124-135.

15. Goodman, L. A., \& Epstein, D. (2020). Loneliness and the CoViD-19 pandemic: Implications for intimate partner violence survivors. Journal of Family Violence, 1-8.

16. Gould, E., \& Wilson, V. (2020). Black Workers Face Two of the Most Lethal Preexisting Conditions for Coronavirus-Racism and Economic Inequality. Economic Policy Institute.

17. Gulati, G., \& Kelly, B. D. (2020). Domestic violence against women and the COVID-19 pandemic: What is the role of psychiatry? International Journal of Law and Psychiatry, 71(May), 101594. https://doi.org/10.1016/j.ijlp.2020.101594 
18. Holmes, E. A., O’Connor, R. C., Perry, V. H., Tracey, I., Wessely, S., Arseneault, L., \& Bullmore, E. (2020). Multidisciplinary research priorities for the COVID-19 pandemic: A call for action for mental health science. The Lancet Psychiatry, 7(6), 547-560. https://doi.org/10.1016/S2215-0366(20) 30168-1

19. Horesh, D., \& Brown, A. D. (2020). Covid-19 response: Traumatic stress in the age of Covid-19: A call to close critical gaps and adapt to new realities. Psychological Trauma: Theory, Research, Practice, and Policy, 12(4), 331-335. https://doi.org/10.1037/TRA0000592

20. Humphreys, J. (2003). Resilience in sheltered battered women. Issues in MentalHealth Nursing, 24(2), 137. https://doi.org/10.1080/01612840390160694

21. Hyland, D. L. (2014). Constructing safer lives: Women who display resilience in responding to intimate-partner violence (IPV).

22. Jarnecke, A. M., \& Flanagan, J. C. (2020). Staying safe during COVID-19: How a pandemic can escalate risk for intimate partner violence and what can be done to provide individuals with resources and support. Psychological Trauma: Theory, Research, Practice, and Policy, 12, 202-204. https://doi.org/10.1037/tra0000688

23. Jetelina, K. K., Knell, G., \& Molsberry, R. J. (2020). Changes in intimate partner violence during the early stages of the COVID-19 pandemic in the USA. Injury Prevention. https://doi.org/10.1136/ injuryprev-2020-043831

24. Johnson, K., Green, L., Volpellier, M., Kidenda, S., McHale, T., Naimer, K., \& Mishori, R. (2020). The impact of COVID-19 on services for people affected by sexual and gender-based violence. International Journal of Gynecology and Obstetrics, 150(3), 285-287. https://doi.org/10.1002/ijgo. 13285

25. Kaukinen, C. (2020). When stay-at-home orders leave victims unsafe at home: exploring the risk and consequences of intimate partner violence during the COVID-19 pandemic. American Journal of Criminal Justice, 45(4), 668-679. https://doi.org/10.1007/s12103-020-09533-5

26. Kessler, R. C., Molnar, B. E., Feurer, I. D., \& Appelbaum, M. (2001). Patterns and mental health predictors of domestic violence in the United States: Results from the national comorbidity survey. International Journal of Law and Psychiatry, 24(4-5), 487-508. https://doi.org/10.1016/S01602527(01)00080-2

27. Kofman, Y. B., \& Garfin, D. R. (2020). Home is not always a haven: The domestic violence crisis amid the COVID-19 pandemic. Psychological Trauma: Theory, Research, Practice, and Policy, 12(S1), S199.

28. Lauve-Moon, K., \& Ferreira, R. J. (2017). An exploratory investigation: Post-disaster predictors of intimate partner violence. Clinical Social Work Journal, 45(2), 124-135. https://doi.org/10.1007/ s10615-015-0572-Z

29. Lefley, H. P., Scott, C. S., Liabre, M., \& Hicks, D. (1993). Cultural beliefs about rape and victims 'response in three ethnic groups. American Journal of Orthopsychiatry, 63(4), 623-632.

30. Leslie, E., \& Wilson, R. (2020). Sheltering in place and domestic violence: Evidence from calls for service during COVID-19. Available at SSRN 3600646.

31. Luthans, F., Avey, J. B., Avolio, B. J., Norman, S. M., \& Combs, G. M. (2006). Psychological capital development: Toward a micro-intervention. J. Organiz. Behav., 27, 387-393. https://doi.org/10. 1002/job.373

32. Luthar, S. S., Cicchetti, D., \& Becker, B. (2000). The construct of resilience: A critical evaluation and guidelines for future work. Child Development, 71(3), 543-562.

33. Management CoSAOoE. (2020). Social distancing doesn't mean safety distancing. Department of Government and Public Affairs. https://www.sanantonio.gov/gpa/News/ArtMID/24373/ArticleID/ 18724/Social-distancing-doesnt

34. Masten, A. S. (2001). Ordinary magic: Resilience processes in development. American Psychologist, 56, 227-239.

35. Mazza, M., Marano, G., Lai, C., Janiri, L., \& Sani, G. (2020). Danger in danger: Interpersonal violence during COVID-19 quarantine. Psychiatry Research, 289(April), 113046. https://doi.org/10. 1016/j.psychres.2020.113046

36. Money J. (2020). Jefferson County experiencing increase in domestic violence crimes during Covid19 pandemic. Jefferson County Sheriff's. https://jeffcosheriffal.com

37. Moreira, D. N., \& Pinto da Costa, M. (2020). The impact of the Covid-19 pandemic in the precipitation of intimate partner violence. International Journal of Law and Psychiatry, 71(May), 101606. https://doi.org/10.1016/j.ijlp.2020.101606 
38. Morris, J. C., McNamara, M. W., \& Belcher, A. (2019). Building resilience through collaboration between grassroots citizen groups and governments: Two case studies. Public Works Management \& Policy, 24(1), 50-62.

39. New York City Police Department. (2020). Domestic violence reports. New York City Police Department. https://www1.nyc.gov/site/nypd/stats/reports-analysis/domestic-violence.page

40. NiCarthy, G. (1982). Getting free: A handbook for women in abusive relationships. Seal Press.

41. Perilla, J. L., Bakeman, R., \& Norris, F. H. (1994). Culture and domestic violence: The ecology of abused Latinas. Violence and victims, 9(4), 325-339.

42. Piquero, A. R., Riddell, J. R., Bishopp, S. A., Narvey, C., Reid, J. A., \& Piquero, N. L. (2020). Staying home, staying safe? A short-term analysis of COVID-19 on dallas domestic violence. American Journal of Criminal Justice, 45(4), 601-635. https://doi.org/10.1007/s12103-020-09531-7

43. Portland Police Bureau. (2020). Trends analysis: pre and post school closures.

44. Rossi, F. S., Shankar, M., Buckholdt, K., Bailey, Y., Israni, S. T., \& Iverson, K. M. (2020). Trying times and trying out solutions: intimate partner violence screening and support for women veterans during COVID-19. Journal of General Internal Medicine, 35(9), 2728-2731. https://doi.org/10. 1007/s11606-020-05990-0

45. Rutter, M. (2013). Annual Research Review: Resilience-clinical implications.Journal of Child Psychology and Psychiatry, and Allied Disciplines, 54(4),474-487. doi:10.111 1/j.1469-7610.2012.02615.x

46. Schultz, P., Roditti, M., \& Gillette, M. (2009). Resilience, social support, and psychological disturbance in Hispanic women residing in a battered women's shelter on the U.S./Mexico border. Hispanic Health Care International, 7(4),224-230. doi: https://doi.org/10.1891/1540-4153.7.4.224

47. Schumacher, T.R. (2017). Resilience and health of older women who have experience intimate partner violence earlier in life. New Mexico State University, ProQuest Dissertations Publishing: 10759029.

48. Silverio-Murillo, A., Balmori de la Miyar, J. R., \& Hoehn-Velasco, L. (2020). Families under Confinement: COVID-19, Domestic Violence, and Alcohol Consumption. SSRN Electronic Journal. https://doi.org/10.2139/ssrn.3688384

49. Stockman, J. K., Hayashi, H., \& Campbell, J. C. (2015). Intimate partner violence and its health impact on ethnic minority women. Journal of Women's Health, 24(1), 62-79.

50. Taub A. (2020). A new COVID-19 crisis: domestic abuse rises worldwide. The New York Times. https://www.nytimes.com/2020/04/06/world/coronavirus-domestic-violence.html

51. Thomas, D. R. (2003). A general inductive approach for qualitative data analysis.

52. Todd, J. L., \& Worell, J. (2000). Resilience in low-income employed African American women. Psychology of Women Quarterly, 24, 119-128.I

53. UN Women. (2020a). COVID-19 and ending violence against women and girls. United Nations, 10. Retrieved from https://www.unwomen.org/-/media/headquarters/attachments/sections/library/publi cations/2020/issue-brief-covid-19-and-ending-violence-against-women-and-girls-en.pdf?la=en \& vs $=5006$

54. UN Women. (2020b). Impact of COVID-19 on violence against women and girls and service provision: UN Women rapid assessment and findings. Retrieved from https://www.unwomen.org/-/media/ headquarters/attachments/sections/library/publications/2020/impact-of-covid-19-on-violence-again st-women-and-girls-and-service-provision-en.pdf?la $=$ en \&vs $=0$

55. Vaismoradi, M., Turunen, H., \& Bondas, T. (2013). Content analysis and thematic analysis: Implications for conducting a qualitative descriptive study. Nursing \& Health Sciences, 15(3), 398-405.

56. Wagnild, G. (2016). The resilience scale user's guide for the US English version of The Resilience Scale and the 14-item Resilience Scale (RS-14). Worden, MT: The Resilience Center.

57. Zhang, L., Zhao, J., Liu, J., \& Chen, K. (2020). Community Disaster Resilience in the COVID-19 Outbreak: Insights from Shanghai's Experience in China. Risk Management and Healthcare Policy, 13,3259 .

Publisher's Note Springer Nature remains neutral with regard to jurisdictional claims in published maps and institutional affiliations. 